\title{
GEOGRAFSKE DIMENZIJE NARAVNIH NESREČ IN VARSTVA PRED NJIMI
}

\author{
Karel Natek \\ Oddelek za geografijo, Filozofska fakulteta, Univerza v Ljubljani, Aškerčeva 2, \\ SI- I000 Ljubljana, Slovenija \\ e-mail: karel.natek@guest.arnes.si
}

Izvirni znanstveni članek

COBISS 1.01

\section{Izvleček}

Z geografskega vidika naravne nesreče niso zgolj izjemni dogodki, temveč so del zapletenega sistema odnosov med naravo in družbo. Geografija jih obravnava kot sestavni del pokrajine, v kateri je možno z geografskimi metodami identificirati njihovo prisotnost, učinke na naravo in družbo ter možne prilagoditve človeške družbe nanje, kar je ključnega pomena za preprečevanje negativnih posledic in eden od predpogojev za smotrno prostorsko načrtovanje in za uveljavitev paradigme sonaravnega razvoja.

Ključne besede: geografija, naravne nesreče, poplave, sonaravni razvoj, prostorsko planiranje, Slovenija.

\section{GEOGRAPHICAL DIMENSIONS OF NATURAL HAZARDS AND THEIR PREVENTION}

\begin{abstract}
From the geographical point of view, natural hazards are not exceptional natural events but part of complex interrelations between nature and society. In geography, they are considered as constituent parts of geographical space and it is possible, by means of geographical methods, to identify their presence, impact on nature and society and possible human adaptations. Such investigations are of vital importance for prevention of their negative effects and as a precondition for responsible spatial planning and implementation of the sustainable development paradigm.
\end{abstract}

Key words: geography, natural hazards, floods, sustainable development, spatial planning, Slovenia. 


\section{UVOD}

Ob vsakem naravnem dogodku, ki postane novica v sodobnih medijih, je vedno znova zanimivo opazovati presenečenost širše javnosti in celo nekaterih strokovnjakov nad 'kruto' naravo, čeprav so odstopanja od povprečja od nekdaj sestavni del naravnega dogajanja. Po eni strani smo pozabili (ali pa sploh ne vemo), da tudi v naših pokrajinah prežijo nevarnosti, zaradi katerih lahko utrpimo škodo ali je moteno naše vsakdanje življenje, po drugi strani pa ne upoštevamo že pridobljenega obsežnega znanja o teh naravnih dogodkih, s katerim bi se lahko marsičemu preprosto izognili. Sodoben način življenja nas je očitno že toliko odmaknil od naravnega dogajanja, da so naše percepcije narave bolj ali manj omejene na neposredne izkušnje iz kratkotrajnega doživljanja narave v prostem času, v obdobjih 'lepega' vremena, in da sploh nismo več sposobni dojemati okolja v njegovi izjemni spremenljivosti in kompleksnosti.

Pogled geografije na naravne nesreče je drugačen: naravne nesreče so pomemben sestavni del pokrajine (geografskega prostora) in jih je potrebno upoštevati tako v vsakdanjem življenju kot pri gospodarskem delovanju, še zlasti pa pri načrtovanju rabe prostora. Velika raznolikost in variabilnost naravnih sistemov ter njihova prepletenost z družbenimi sistemi ustvarjajo po eni strani pestrost slovenskih pokrajin, na katero smo lahko upravičeno ponosni, po drugi strani pa otežkočajo identifikacijo naravnih procesov ali dogodkov, ki bi lahko ljudem povzročili 'nevšečnosti' oziroma težave ali v skrajnih primerih celo škodo in človeške žrtve. Z geografskimi metodami preučevanja je možno identificirati prisotnost teh procesov v pokrajini, opredeliti njihove učinke na naravo in družbo ter na tej osnovi, $v$ povezavi z drugimi strokami, tudi poiskati možnosti 'sobivanja' z njimi prek instrumentov prostorskega in drugih oblik načrtovanja.

\section{NARAVNE NESREČE KOT PREDMET GEOGRAFIJE}

Naši predhodniki geografi so bili v Sloveniji prvi, ki so začeli preučevati naravne nesreče ne kot posamične izjemne dogodke, temveč kot eno od sestavin zapletenega odnosa med naravo in družbo v konkretni pokrajini. To je bila celo ena temeljnih nalog nekdanjega Inštituta za geografijo pri Slovenski akademiji znanosti in umetnosti (današnji Geografski inštitut A. Melika ZRC SAZU), pozneje pa so se geografom pridružile še druge stroke. Za prvi celoviti preučitvi večjih naravnih nesreč veljata študiji vzrokov in posledic poplave junija 1954 v Celju, pri kateri je sodelovala večja skupina geografov in drugih strokovnjakov pod vodstvom A. Melika (Melik in sod. 1954), ter Gamsova študija o snežnih plazovih v zimah 1950-54 (Gams 1955). V naslednjih letih je v Geografskem zborniku in Geografskem vestniku izšla vrsta poglobljenih študij o vremenskih ujmah, poplavah, zemeljskih in snežnih plazovih, potresih in drugih naravnih nesrečah, po letu 1987 pa so se tovrstni prispevki skoncentrirali v strokovni reviji Ujma, ki jo izdaja Uprava Republike Slovenije za zaščito in reševanje (Natek 2002, 62). Če izvzamemo poplave 1. novembra 1990, ki jim je posvečena skoraj celotna peta številka revije Ujma in prinaša tudi vrsto geografskih prispevkov, lahko 
ugotovimo, da po eni strani nekoliko usiha zanimanje geografov za problematiko naravnih nesreč, predvsem pa se stopnjuje angažiranost drugih strok pri preučevanju te problematike. Slednje seveda ni slabo, saj je za razumevanje naravnih nesreč ter njihovih učinkov v pokrajini in za človeško družbo nujno potreben interdisciplinarni pristop, vendar pa pri tem ne sme manjkati celovit geografski pristop, še zlasti ne pri uveljavitvi spoznanj o vzročnoposledičnih povezavah med pokrajinskimi sestavinami (vključno z naravnimi nesrečami) na področju preventivnega delovanja in prostorskega načrtovanja.

Eden najpomembnejših rezultatov geografskega preučevanja naravnih nesreč je nedvomno ugotovitev, »... da so takšni dogodki/procesi (naravne nesreče) sestavni del naravnega dogajanja, ki ga človek praviloma ne more preprečiti, temveč se mu mora na čim ustreznejše načine prilagoditi (Natek 2002, 63). Po mnenju Gamsa nas geografe zanimajo predvsem tiste prilagoditve, ki »... pomagajo ustvarjati podobo pokrajine« (Gams 1983, 13), saj postane s temi prilagoditvami prisotnost tovrstnih naravnih dogodkov pomembna sestavina vsake kulturne pokrajine.

Natek (2002) ugotavlja štiri pokrajinske sestavine, ki so tako ali drugače povezane s prisotnostjo naravnih nesreč v pokrajini:

- neposredni učinki naravnih dogodkov/procesov (npr. zemeljski plazovi, podorne skale, hudourniški vršaji idr.),

- $\quad$ sestavine, ki kažejo, da se je človek zavedal nevarnosti teh naravnih dogodkov in se je izognil ogroženim območjem (npr. snežnim plazovom, rednim poplavam, recentnim hudourniškim vršajem),

- varovalni objekti (npr. gradnja na umetno nasutih tleh, potresnovarna gradnja, razbremenilni kanali),

- negativne izkušnje ob naravnih nesrečah (npr. napačno zgrajeni mostovi na Selški Sori in pritokih, ob katerih je plavje zajezilo strugo in povečalo poplave, odnašanje z velikimi skalami utrjenih brežin, erozija prsti).

Naravne nesreče pogosto niso neposredno vidne v pokrajini, saj gre večinoma za kratkotrajne pojave (z izjemo suše), zaradi česar jih je v obdobjih med dogodki precej težko identificirati. In ravno tu se najbolj izkažejo geografske metode preučevanja, saj lahko z njimi identificiramo in pojasnimo npr. vzročno-posledične povezave znotraj pokrajine, povezave med naravnimi in družbenimi dejavniki, razlike v prostorski razporeditvi pojavov ali spreminjanje pojavov in njihovih medsebojnih odnosov skozi čas.

$\mathrm{S}$ težavno identifikacijo naravnih nesreč $\mathrm{v}$ pokrajini je neposredno povezano tudi subjektivno zaznavanje naravnih nesreč v prostoru in času tako pri lokalnem prebivalstvu kot tudi med načrtovalci prostorskega razvoja (Natek 2002). Gašperič $(2004,13)$ npr. navaja, da kar $72 \%$ anketiranih prebivalcev južnega dela Ljubljane sploh ni vedelo, da so na njihovem območju bivanja možne poplave, 59 \% pa ni vedelo, da je bilo to območje v preteklosti že poplavljeno. Katastrofalne poplave v letih 1885, 1888, 1895, 1926 in 1933 torej ne obstajajo več niti v strukturi sedanje primestne pokrajine, niti v zavesti tamkajšnjih prebivalcev. 
Slika 1: Kmetijska raba poplavnih ravnic je možna, a povezana s tveganjem - na sliki poplavljen rastlinjak na poplavni ravnici Hudinje v Arclinu (K. Natek; 19.9.2007).

Figure 1: Agricultural use of floodplains is possible but associated with risk of flooding - a damaged greenhouse in Hudinja River floodplain in the village of Arclin (K. Natek; 19.9.2007).

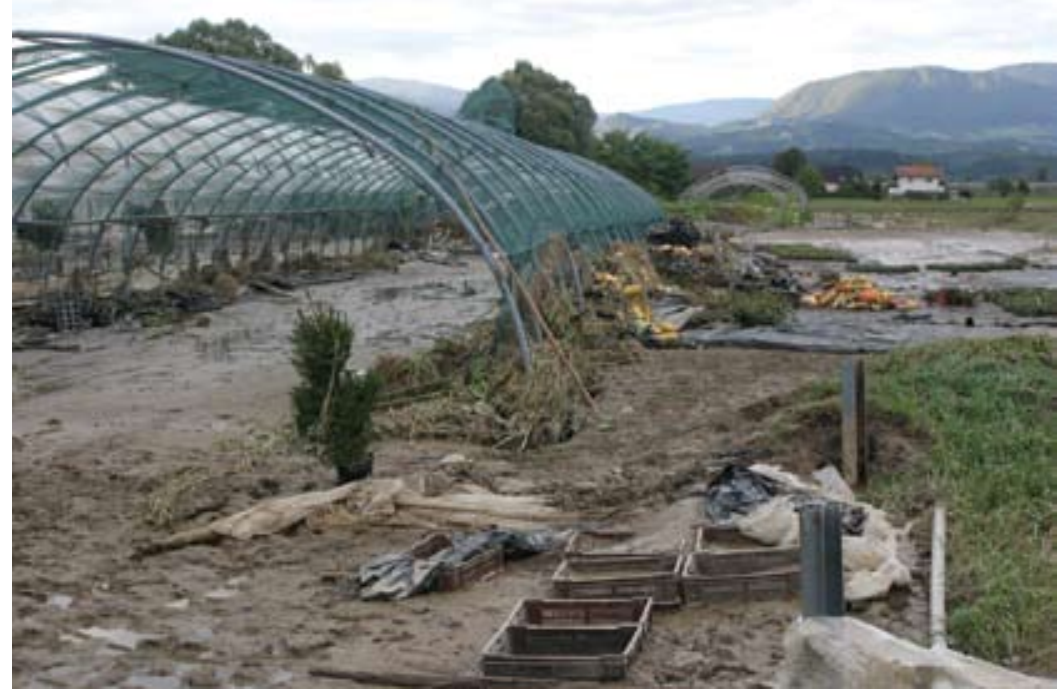

Slika 2: Stanovanjska hiša tik ob Malem grabnu na poplavnem območju v južnem delu Ljubljane (K. Natek; 10.10.2004).

Figure 2: A house close to Mali Graben on floodplain in southern part of Ljubljana (K. Natek; 10.10.2004).

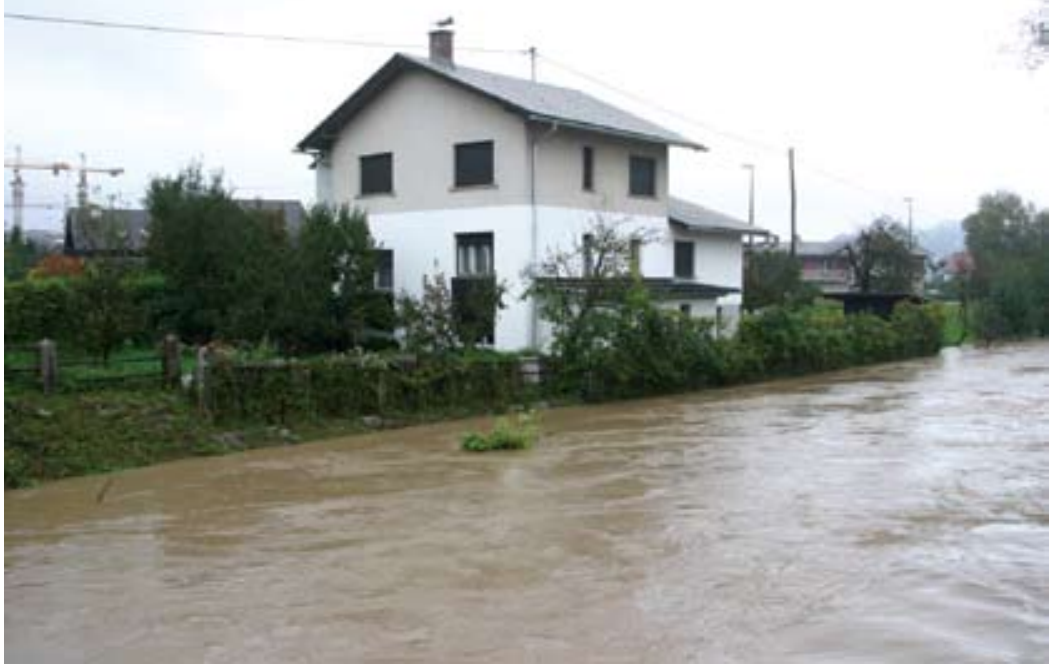




\section{PROGNOSTIČNI PRISTOP K PREUČEVANJU NARAVNIH NESREČ}

Izraz 'prognostična geografija' je Radinja (1983a) uvedel prav v povezavi s preučevanjem naravnih nesreč. V tem sklopu mu prognostična geografija pomeni »... prikaz njihove regionalizacije, izrazitosti, frekvenčnosti in ustreznih režimov, kar pomeni hkrati opredelitev ustrezne ogroženosti pokrajine, kar pa ni več daleč od prognoziranja.« (Radinja 1983a, 28). Pri tem gre pravzaprav za vrednotenje določenega pojava ali/in njegove funkcije v pokrajini, ki mora sicer izhajati iz dosedanjega razvoja pojava samega (tudi navidezno počasni in nespremenljivi naravni procesi močno variirajo in se spreminjajo s časom, kar bomo najbolj občutili s stopnjevanjem globalnih klimatskih sprememb), a hkrati zahteva upoštevanje obstoječe družbene stvarnosti ter dinamike njenega hitrega spreminjanja.

S splošnim družbenim razvojem se temeljito spreminjajo tudi razmerja med naravo in družbo. Še nedolgo tega 'gospodarji narave' se počasi začenjamo zavedati, da bomo preživeli samo z uveljavitvijo trajnostnega razvoja, ki temelji na upoštevanju naravnih danosti in omejitev. To je, sicer v kontekstu takratnega 'oblastniškega' odnosa do narave, razumel že A. Melik, a moramo že več kot pol stoletja zatem še vedno opozarjati na iste napake v našem odnosu do narave: »Dandanes pa je tako, da je človek v ogromni meri obvladal prirodne sile in se mu ni treba več toliko ozirati nanje. Pri tem je pač napravil tudi napako, da se premalo zanima zanje in jih ne upošteva tudi ne v tistem obsegu, kjer mu lahko škodijo, če je premalo previden.« (Melik, 1954, 22-23).

Hkrati z družbenim razvojem se spreminjajo tudi naravne nesreče in celo pojavljajo nove, kar je še en dokaz, da ti dogodki/procesi niso izključno fizičnogeografski pojav/problem, pač pa se ravno v tem dvosmernem odnosu izrazito kaže njihova 'geografskost' v najširšem pomenu besede (primer iz politične geografije: osamosvojitev Bangladeša in razpad Pakistana po katastrofalnem tropskem ciklonu novembra 1970, ki je zahteval ok. 266.000 žrtev).

Naj navedem še dva primera: ob potresu 14. aprila 1895 je imela Ljubljana samo ok. 30.000 prebivalcev (danes več kot 260.000) in je bila v takratni državi precej nepomembno središče ene od gospodarsko najbolj zaostalih pokrajin, danes pa je glavno mesto države z izjemno koncentracijo gospodarskih, finančnih, intelektualnih in drugih potencialov. Te družbenogeografske spremembe so tako velike, da bi imel (geofizikalno) podoben dogodek (magnituda 6,1,jakost 8.-9. stopenj po EMS-98) povsem drugačne posledice in je kakršna koli ekstrapolacija učinkov takratnega potresa na današnje razmere povsem nemogoča, še zlasti če izhajamo iz dejstva, da je možnost preživetja ljudi in stopnja prizadetosti infrastrukturnih sistemov najbolj odvisna od upoštevanja zakonsko določene potresno varne gradnje, tega pa za veliko večino objektov v Ljubljani ne vemo (Orožen Adamič 1995).

Drug primer temeljitega spreminjanja odnosa med naravo in družbo so t.i. magnetni viharji, začasna oslabitev zemeljskega magnetnega polja zaradi močnih izbruhov na Soncu, ki jih poznamo šele nekaj desetletij in lahko v nekaj trenutkih sesujejo elektroenergetska, telekomunikacijska, navigacijska in druga omrežja na velikih območjih (npr. izpad električnega omrežja v večjem delu Québeca, Kanada, 13.3.1989). 
Prognostični pristop pri geografskem preučevanju naravnih nesreč ima seveda omejen domet in tega se je že pred več kot 20 leti zavedal tudi Radinja (1983a, 28): »Ko omenjam prognostično geografijo, ne mislim na verjetnost ali predvidevanje posameznih pojavov, vključno s katastrofami, temveč na prognoziranje širšega pokrajinskega razvoja.« Sprašuje se, ali ima geografija za to ustrezne metodološke in druge osnove, mi pa lahko dodamo še vprašanje, ali naša družba takšne prognoze sploh potrebuje?

Slika 3: Poplavna ravnica Gradaščice pri vasi Hrastenice (K. Natek; 10.10.2004).

Figure 3: Floodplain of the Gradaščica River near the village Hrastenice (K. Natek; 10.10.2004).

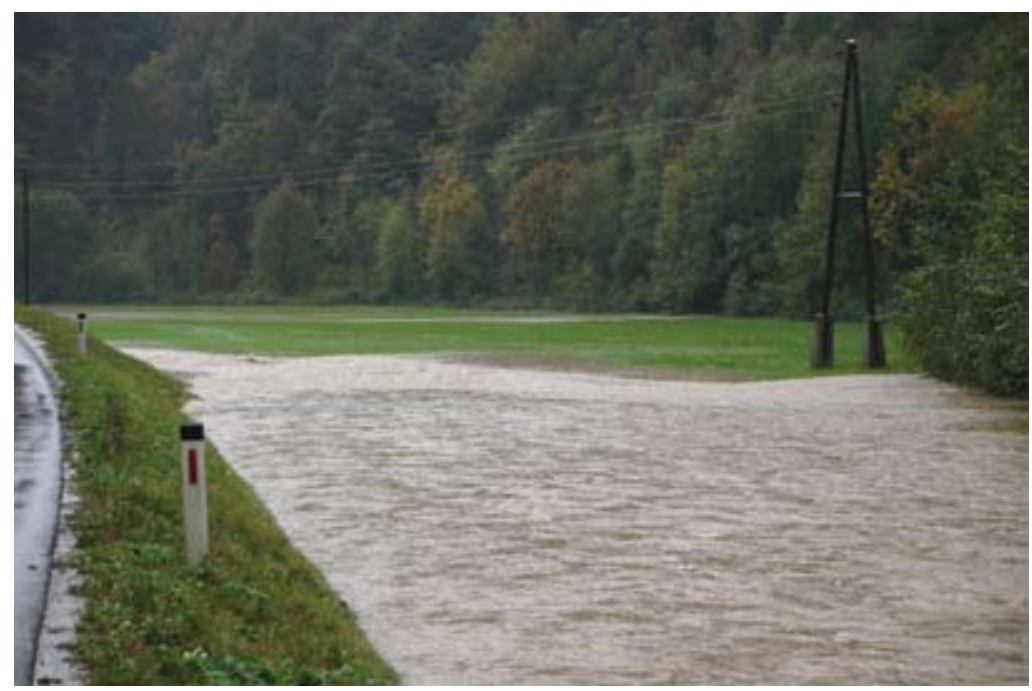

Odgovor na obe vprašanji je po mojem mnenju pritrdilen, a z določenimi zadržki. Rezultati geografskega preučevanja so zaradi kompleksnosti in navidezne splošnosti, ki izvira iz predmeta preučevanja samega, včasih za negeografe težko razumljivi ali premalo natančni in namesto njih rajši posežejo po parcialnih, izrazito analitično pridobljenih, vendar numeričnih podatkih, tudi kadar temeljijo na zelo kratkih opazovalnih nizih ali zgolj ekspertnih ocenah. Kot klasičen primer tega neskladja navaja že Radinja (1983a, 25-26; 1983b) žled novembra 1980 v Brkinih, ki je poleg 'običajne’ škode v gozdovih, sadovnjakih in na električnem omrežju porušil tudi novozgrajeni jugoslovanski 380-kilovoltni daljnovod. Njegovi načrtovalci 'niso imeli' na razpolago natančnih podatkov o pojavljanju žleda, bilo pa je splošno poznano pri domačinih, gozdarjih, geografih (Šifrer 1977) in drugih, da se žled zelo pogosto pojavlja na celotni dinarski gorski pregradi in tudi v Brkinih.

Pri odgovoru na drugo vprašanje smo lahko nekoliko bolj kritični, saj v naši družbi očitno prevladuje mnenje, da takšnih 'geografskih prognoz' ne potrebujemo, marsikdaj pa potencialni uporabniki niti ne vedo, da sploh obstajajo. Rezultati dolgoletnega raziskovalnega projekta Proučevanje poplavnih področij na Slovenskem, ki ga je v letih 1972-1985 vodil 
sedanji Geografski inštitut Antona Melika ZRC SAZU, so bili objavljeni v več kot dvajsetih obsežnih študijah v Geografskem zborniku, vendar žal niso našli poti v praktično uporabo. Sicer so bila predmet preučevanja skoraj vsa večja poplavna območja v Sloveniji in ne posamične poplave, vendar pa je bil v študijah velik poudarek tudi na 'prognostičnih' podatkih, pridobljenih s terenskim preučevanjem in zbiranjem najrazličnejših podatkov o preteklih največjih poplavah. Avtorji so pri tem izhajali iz hipoteze, da lahko na osnovi preteklih poplav napovemo obseg, intenzivnost in druge značilnosti prihodnjih poplav, torej iz povsem enake hipoteze kot se uporablja pri statističnem izračunavanju 20-, 50- in 100 -letnih poplav na osnovi večletnih nizov meritev vodostajev oziroma pretokov na mreži državnih vodomernih postaj.

Slika 4: Poplavljena tovarna barv JUB v Vidmu pri Ljubljani (K. Natek; 5.11.1998).

Figure 4: Flooded industrial complex JUB in Videm near Ljubljana (K. Natek; 5.11.1998).

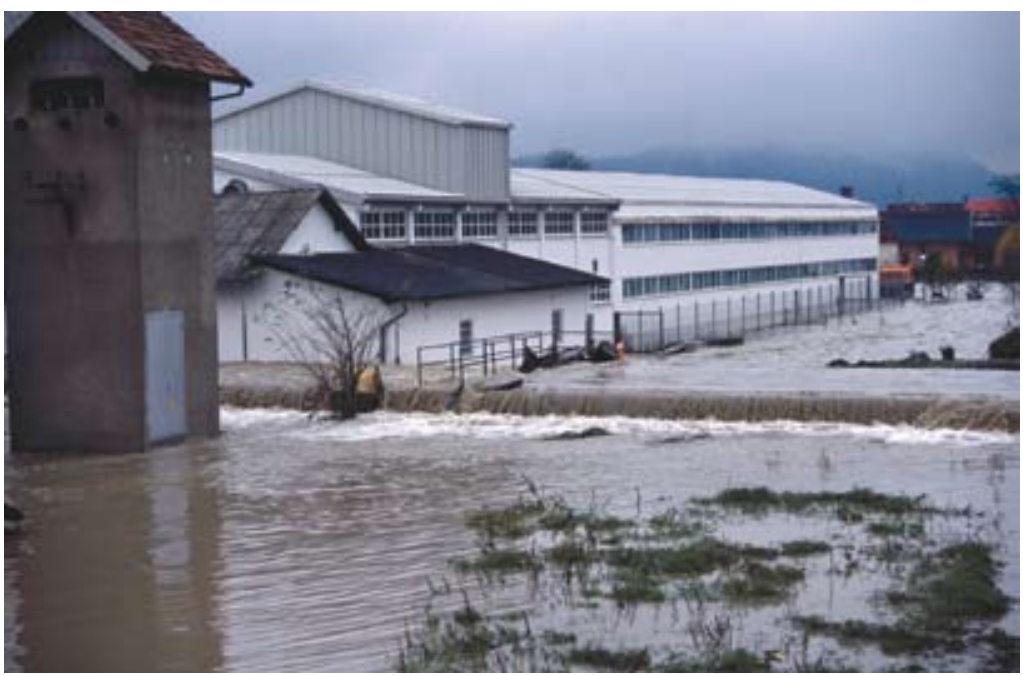

Kot že rečeno, so 'prognostične zmožnosti' geografije omejene in s svojimi metodami lahko pri posameznih vrstah naravnih nesreč sežemo različno daleč. Tudi z geografskimi metodami ne moremo napovedati, kdaj in kje se bo zgodila naslednja naravna nesreča, lahko pa s tovrstnimi preučevanji uspešno identificiramo območja, na katerih je povečana verjetnost pojavljanja prihodnjih naravnih nesreč, kar je tudi po Radinjevem mnenju (1983a) pomemben prispevek k prognostični geografiji.

Podobno kot seizmologija smo tudi geografi precej šibki pri napovedovanju učinkov prihodnjih potresov, saj je edini učinkoviti ukrep doslej ustrezna protipotresna gradnja, vendar lahko kar dobro napovemo območja in učinke prihodnjih poplav, snežnih plazov, žleda, suš in drugih vremenskih ujm, dobro so poznana plazovita območja in erozijska žarišča ipd. Sledovi tovrstnih preteklih dogodkov ali opozorila o teh pojavih »... so marsikdaj zapisana v pokrajini in pomembna naloga geografov ter drugih raziskovalcev je, da jih spoznamo in pripravimo 
za uporabo pri nadaljnjih posegih...« (Natek 2005, 17). Že Zgolj z večjo dovzetnostjo družbe za te izkušnje in znanje, bi se izognili marsikateremu napačnemu posegu v prostor, koristno pa bi bilo tudi bolj upoštevati splošne zakonitosti pojavljanja naravnih procesov/nesreč, saj lahko to védenje $\mathrm{v}$ določenih razmerah nadomesti pomanjkanje eksaktnih kvantitativnih podatkov.

\section{NARAVNE NESREČE IN SONARAVNI RAZVOJ}

Pokrajina (geografsko okolje) »predstavlja prostorsko areno in naravni (naravni viri) oziroma širše, okoljski kapital (viri okolja, vključno s storitvami okolja, ekosistema) človekove blaginje.« (Plut 2004, 22). V interesu družbe je, da zasleduje ».. . cilj, težnjo trajnega oziroma trajnostnega ohranjanja naravnega (okoljskega) kapitala in hkrati dolgoročno (trajno) zasnovanega delovanja gospodarstva in celotne družbe.« (Plut 2004, 22). Ker pa je "geografija prostorska veda, v ospredje postavlja proučevanje sestave in dinamike pokrajine ter razmerja med človekom in naravo (okoljem), ne pa sicer prav tako pomembne socialne (socialna varnost) in ekonomske (dvig materialnega blagostanja) razsežnosti trajnostnosti... Zato je primerno, da geografsko proučevanje poudari pomen pokrajinskim (regionalnim) okoljskim, naravnim značilnostim in procesom čim bolj prilagojenega, torej sonaravnega razvoja poselitve, gospodarstva, infrastrukture in pokrajinske rabe.« (Plut 2004, 23).

Uveljavitev prostorske dimenzije v kontekstu paradigme trajnostnega (sonaravnega) razvoja je za geografijo velikega pomena, saj vnaša vanjo kompleksnost pokrajin (okolja, prostora), predvsem z vidika dvosmernega součinkovanja med naravo in družbo, ter raznolikost 'prostorske arene' (Plut 2004, 22), v kateri delujejo poleg naravnih še najrazličnejši družbenogeografski, sociološki, ekonomski idr. sistemi. Že Plut (2005. 101) je ugotovil, da je bila doslej prostorska in/ali pokrajinska razsežnost trajnostnega razvoja v precejšnji meri zapostavljena, tako da je lahko prispevek geografije $\mathrm{v}$ »... poudarjanju pomena pokrajinskim potezam in procesom čim bolj prilagojenega-sonaravnega vzorca poselitve, gospodarstva, infrastrukture in pokrajinske rabe.«

Naravni in družbeni procesi ne potekajo v nekem abstraktnem, enakomernem prostoru, marveč so hkrati vzrok in posledica raznolikosti pokrajine (prostora), v kateri imajo posamezni deli različno dinamiko in različne funkcije. Upoštevanje tega dejstva s strani družbe je lahko pomemben prispevek k stabilnejšemu, sonaravnemu razvoju, saj »regionalno (ali lokalno) pojmovana sonaravnost ... pomeni prilagajanje dejavnosti človeka regionalnim omejitvam in trajno rabo virov regije na način, ki ne bo ogrozil delovanja regije, sosednjih območij in obremenjeval planetarni ekosistem.« (Plut 2005, 65).

$Z$ vidika naravnih nesreč zaslužijo največjo pozornost tisti deli pokrajine (prostora), kjer je intenzivnost naravnih procesov posebno močna in je $\mathrm{z}$ vidika sonaravnega razvoja smotrno, da se pri udejanjanju takšnega razvoja da prednost naravnim procesom pred trenutnimi potrebami družbe, čeprav pri tem ni prvenstveni cilj varovanje narave, temveč varovanje človeka (družbe) pred destruktivnim (škodljivim) delovanjem naravnih procesov. Umeščanje neustreznih dejavnosti v takšna območja je žal močno razširjena praksa povsod po svetu, vendar pa trajnostnega/sonaravnega razvoja ne moremo udejaniti brez zagotav- 
Slika 5: Viharni veter in toča sta 17. avgusta 2007 uničila velike hmeljske nasade pri Braslovčah v Spodnji Savinjski dolini (K. Natek; 18.8.2007).

Figure 5: Stormy winds and hail on 17 August 2007 have completely destroyed hops plantations near Braslovče in the Lower Savinja Valley (K. Natek; 18.8.2007).

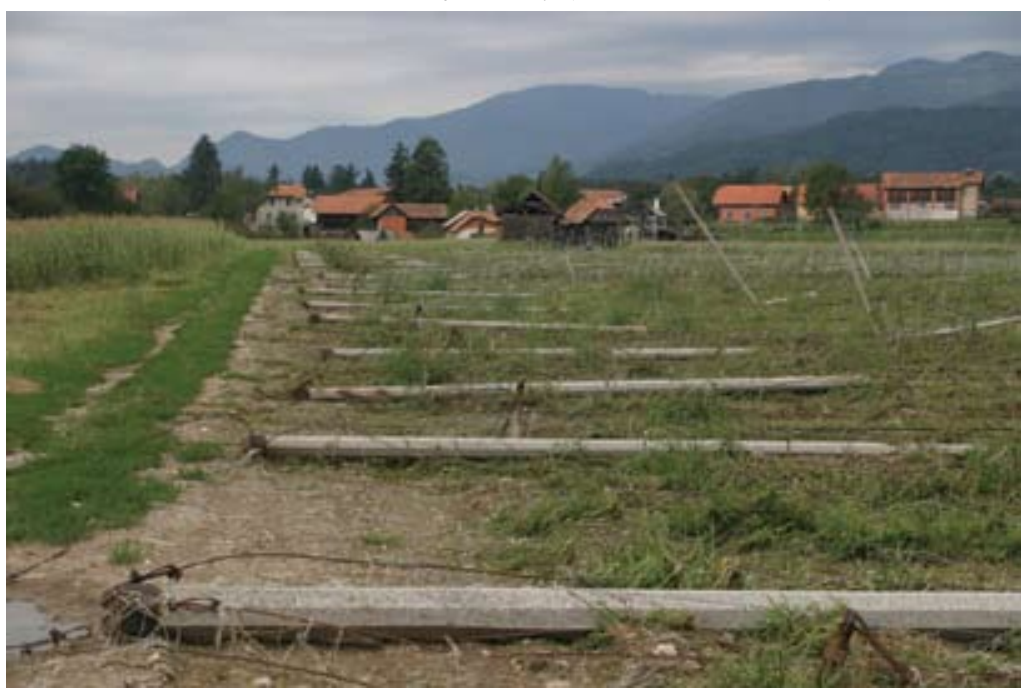

Slika 6: Odpravljanje posledic poplave 18. septembra 2007 v novem stanovanjskem naselju v poplavni ravnici Bolske v Preboldu (K. Natek; 19.8.2007).

Figure 6: Cleaning after floods of 18 September 2007 in a new residential area of Prebold, situated in the floodplain of Bolska River (K. Natek; 19.8.2007).

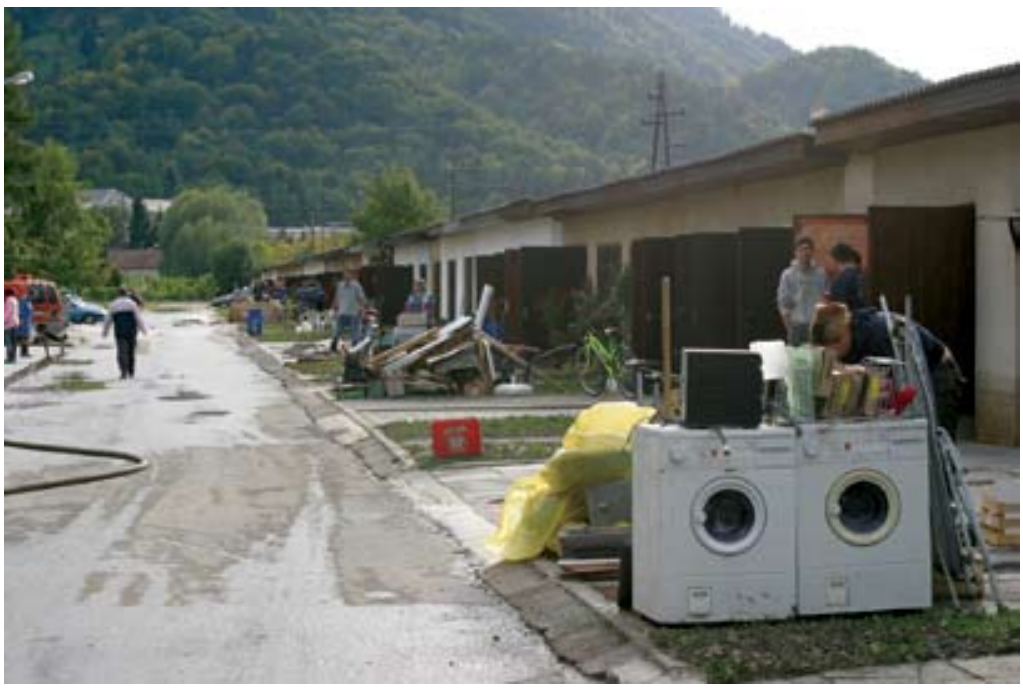


ljanja ustrezne funkcionalnosti prostora (ali njegovih delov), saj »...sonaravni razvoj-napredek pomeni usmeritev prostorskega, gospodarskega in regionalnega razvoja $\mathrm{v}$ okviru (različnih) zmogljivosti (omejitev) geografskega okolja, pokrajine. Obsega razvoj poselitve, gospodarstva, infrastrukture in pokrajinske rabe hkrati z varstvom (bivalnega) okolja, varstvo naravnih virov, varstvo narave oziroma ohranjanje pokrajinske, ekosistemske, vrstne pestrosti.« (Plut 2005, 99).

Širjenje južnega dela Ljubljane na poplavno območje ob Gradaščici in Ljubljanici je značilen primer neuresničevanja načela trajnostnega razvoja v praksi (Natek 2002, 70-71; Gašperič 2004). Še na začetku 60. let 20. stoletja je mesto segalo le na skrajni severni rob Ljubljanskega barja (Trnovo) in nekoliko dlje vzdolž Tržaške ter Dolenjske ceste, nato pa je sledila načrtna, vendar $z$ vidika poplavne nevarnosti povsem neustrezno locirana in izvedena gradnja velikega naselja pritličnih enodružinskih hiš v Murglah ter stihijska, nenačrtna urbanizacija vzdolž Ceste dveh cesarjev, Ižanske ceste ter na območju Sibirije in Rakove jelše. Po 1990 so velik del črnih gradenj legalizirali in s tem še stopnjevali pritisk na južno obrobje mesta, ki ga verjetno ne bo zaustavila niti južna obvoznica. S tem se je število prebivalcev na poplavno ogroženem območju v nekaj desetletjih povečalo z nekaj tisoč na več kot 30.000 (Dobravc 2003).

Hitro širjenje južnega dela Ljubljane na poplavno močno ogroženo območje je proces, ki ni v skladu s paradigmo sonaravnega razvoja, saj obstoječe stanje že močno otežkoča, ali morda celo preprečuje $s$ takšnim razvojem usklajeno reševanje poplavne problematike $\mathrm{v}$ tem delu mesta. Tudi predvidena 'prestavitev' varovanja tega dela Ljubljane na gorvodna območja $\mathrm{v}$ porečju Gradaščice, kjer naj bi v ta namen zgradili več velikih zadrževalnikov poplavnih voda, ni v skladu s to paradigmo, saj prenaša (okoljsko) breme varovanja na druga območja in drugo prebivalstvo, ki bi se jim zaradi tega zmanjšala kvaliteta bivalnega okolja (Poplavna ogroženost... 2007).

Ker se v zadnjem času veliko govori o gradnji umetnih zadrževalnikov poplavnih voda tudi na drugih vodotokih (npr. na Selški Sori nad Železniki, na Savinji in njenih pritokih v Spodnji Savinjski dolini), je potrebno opozoriti, da je takšen pristop načeloma v nasprotju z določili Direktive 2007/60/ES Evropskega parlamenta in sveta o oceni in obvladovanju poplavne ogroženosti (v veljavi od 26. novembra 2007), ki zahteva od članic EU, da $\gg .$. bi morali v načrtih, kolikor je mogoče, upoštevati ohranjanje in/ali obnovo poplavnih območij...« (14. točka preambule), oziroma da »države članice določijo ustrezne cilje za obvladovanje poplavne ogroženosti na območjih ... s poudarkom na ne gradbenih ukrepih in/ali na ukrepih za zmanjšanje verjetnosti nastopa poplavljanja.« (7. člen, 2. alineja).

Radikalni posegi $\mathrm{v}$ naravne procese odtekanja voda in s tem neločljivo povezanega transporta plavja, kar umetni zadrževalniki poplavnih voda vsekakor so, zahtevajo izjemno velike posege v ekološko, rekreacijsko, pokrajinsko in gospodarsko pomembna dolinska dna ob srednje velikih vodotokih. Zaradi velikih okoljskih in finančnih stroškov bi morali biti takšni posegi najbolj skrajna rešitev, ko res ne bi bilo nobene druge možnosti za zmanjšanje poplavne nevarnosti, zato se takšnih rešitev ne bi smelo sprejemati od primera do primera kot je obstoječa praksa, temveč bi morali izhajati iz celovite strategije zmanjšanja ogroženosti zaradi poplav. Če sodimo po dosedanjih učinkih številnih protipoplavnih ukrepov po Sloveniji (mdr. so njihove pomanjkljivosti razkrile poplave na severnem obrobju Celja 18. sep- 
tembra 2007), bo gradnja protipoplavnih zadrževalnikov brez celovite strategije vnesla v prostor zgolj (lažni) občutek 'popolne' varnosti pred poplavami in s tem še močnejše širjenje naselij, infrastrukture in drugega na poplavne ravnice, to pa bo prineslo ravno nasprotno od pričakovanega - povečanje dolgoročne poplavne ogroženosti, tudi v kontekstu globalnega spreminjanja podnebja.

Tudi dokument Najboljše prakse za preprečevanje poplav, varstvo pred njimi in ublažitev njihovih posledic (2002), ki so ga pripravile nekatere članice EU na osnovi dolgoletnih lastnih negativnih izkušenj, pravi: »Kolikor je to mogoče, je treba ustaviti človekovo vmešavanje v naravne procese, ga nevtralizirati in v prihodnje preprečiti.« (str. 2) »... Treba je podpirati in usklajevati spremembe vodnih politik in rabe prostora, različnih načinov varstva okolja in ohranjanja narave, da bi izboljšali obvladovanje poplav v okviru celostnega upravljanja povodij.« (str. 6) »Če upoštevamo razvoj in težnje, vidimo, da moramo pri obravnavi naravnih nevarnosti spremeniti svojo miselnost. Preiti moramo od defenzivnih ukrepov proti nesrečam k obvladovanju tveganja in zaživeti z dejstvom, da so poplave neizogibne.« (str. 6).

V Sloveniji smo že pred tem dokumentom prišli do podobnih spoznanj in jih vključili v Strategijo prostorskega razvoja Slovenije (2004), vendar pa se tehtna določila strategije zaradi drugačnih razvojnih prioritet niso uveljavila $\mathrm{v}$ praksi prostorskega načrtovanja. $\mathrm{V}$ strategiji je namreč povsem jasno zapisano: »Naravne procese, ki lahko ogrožajo poselitev in človekove dejavnosti, se obvezno upošteva kot omejitev pri načrtovanju rabe in dejavnosti v prostoru. Prostorski razvoj na vseh območjih, zlasti pa na ogroženih območjih, se načrtuje v skladu z omejitvami zaradi naravnih in drugih nesreč, kot so poplave, zemeljski in snežni plazovi, erozija, požari v naravnem okolju in potresi. Potencialna tveganja se zmanjšuje s preventivnim načrtovanjem, in sicer $\mathrm{z}$ razmeščanjem dejavnosti v prostor izven območij potencialnih nesreč, $\mathrm{z}$ ustreznim upravljanjem primarnih dejavnosti v nevarnih in ogroženih območjih ter z nadzorovanjem aktivnosti, ki lahko povzročajo naravne in druge nesreče.« (Strategija, 2004, 30).

Podobno strog je do posegov v poplavna območja Zakon o vodah (2002): »Rabo in druge posege $v$ vode, vodna in priobalna zemljišča ter zemljišča na varstvenih in ogroženih območjih ... je treba programirati, načrtovati in izvajati tako, da se ne poslabšuje stanja voda, da se omogoča varstvo pred škodljivim delovanjem voda, ohranjanje naravnih procesov, naravnega ravnovesja vodnih in obvodnih ekosistemov, ter varstvo naravnih vrednot in območij, varovanih po predpisih o ohranjanju narave.« (5. člen). Na osnovi tega izhodišča po tem zakonu »Na vodnem in priobalnem zemljišču (vključuje tudi poplavne ravnice; op.p.) ter na območju presihajočih jezer ni dovoljeno posegati v prostor, razen...« v nekaterih izrecno določenih primerih (npr. gradnja javne infrastrukture, objektov za varstvo voda pred onesnaževanjem, ukrepi za izboljšanje hidromorfoloških in bioloških lastnosti voda ali ukrepe za ohranjanje narave) (37. člen).

Če bi vsa ta zakonska določila dosledno uresničevali v praksi, se nam ne bi dogajalo, da so ob vsaki večji poplavi poleg starejših stanovanjskih, gospodarskih in drugih objektov poplavljeni in poškodovani tudi mnogi novozgrajeni objekti, ki nikoli ne bi smeli stati na 'območjih škodljivega delovanja voda', še zlasti ne v primerih, ko je tudi na nivoju občine kot pomembnega dejavnika prostorskega načrtovanja na razpolago dovolj površin z bistveno večjo stopnjo varnosti pred škodljivim delovanjem naravnih procesov (Privšek, 2007). 
Ključna napaka je v tem, da se pri poseganju v takšna območja gledajo izključno parcialni in kratkoročni, kar je že dolgo tega ugotovil tudi Radinja $(1983,27)$ : ॥Večkrat neustrezno pojmovanje naravnih pokrajinskih potez zgovorno ilustrira ugotovitev, da se je zemlji priznavala kvečjemu njena tržna vrednost, ne pa mnogo širša z ekološko vred, kar vse prevečkrat velja tudi za vode, zrak in druge sestavine naravnega okolja.«

Slika 7: Ob poplavi 18. septembra 2007 uničen betonski most na lokalni cesti v dolini potoka Davča (K. Natek; 23.9.2007).

Figure 7: During the floods of 18 September 2007 destroyed concrete bridge on local road in the valley of Davča brook (K. Natek, 23.9.2007).

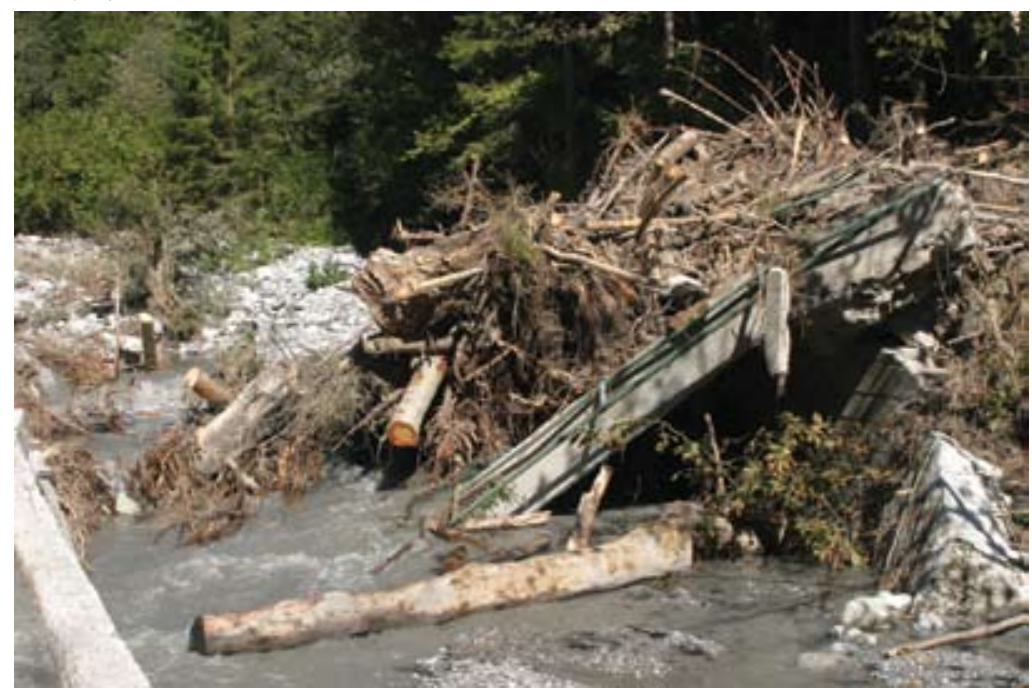

V Sloveniji lahko najdemo na stotine primerov legalnih stanovanjskih, gospodarskih in drugih novogradenj na poplavnih in plazovitih območjih, čeprav so tovrstne novogradnje na teh območjih zakonsko prepovedane. Čeprav je v novem Zakonu o prostorskem načrtovanju (2007) ključni cilj prostorskega načrtovanja »...omogočati skladen prostorski razvoj z obravnavo in usklajevanjem različnih potreb in interesov razvoja $\mathrm{z}$ javnimi koristmi na področjih varstva okolja, ohranjanja narave in kulturne dediščine, varstva naravnih virov, obrambe in varstva pred naravnimi in drugimi nesrečami« (3. člen), tega v našem prostoru skoraj ni opaziti, še več, zasebni interes je v sedanjem času očitno pomembnejši od javnega.

To je z vidika sonaravnega razvoja in t.i. okoljske etike nesprejemljiva praksa, saj »... prostorsko načrtovanje ne bi smelo gledati samo na zadovoljevanje potreb obstoječe družbe po prostoru, temveč bi moralo v smislu t.i. okoljske etike upoštevati tudi medgeneracijsko odgovornost« (Plut 2005, 62). Neupoštevanje prisotnosti naravnih nesreč v pokrajini namreč bistveno zmanjšuje zmogljivost okolja in njegove samoregulacijske zmožnosti, kar se navsezadnje kaže v vse večji škodi zaradi naravnih nesreč in tudi v družbeni nestabilnosti oziroma nepravičnosti, saj se izključno pridobitniški odnos do zemljišč z intenzivnimi na- 
ravnimi procesi kaže v večji labilnosti naravnih procesov in njihovih učinkih na drugih krajih ali v drugačnih oblikah, kar potem plačujejo ne po lastni krivdi prizadeti ljudje oziroma celotna družba prek izdatkov državnega in občinskih proračunov in, ne nazadnje, tudi s humanitarno pomočjo.

Slika 8: Čiščenje središča Železnikov dan po katastrofalni poplavi 18. septembra 2007 (K. Natek; 19.9.2007).

Figure 8: Cleaning of centre of Železniki day after catastrophic floods of 18 September 2007 (K. Natek; 19.9.2007).

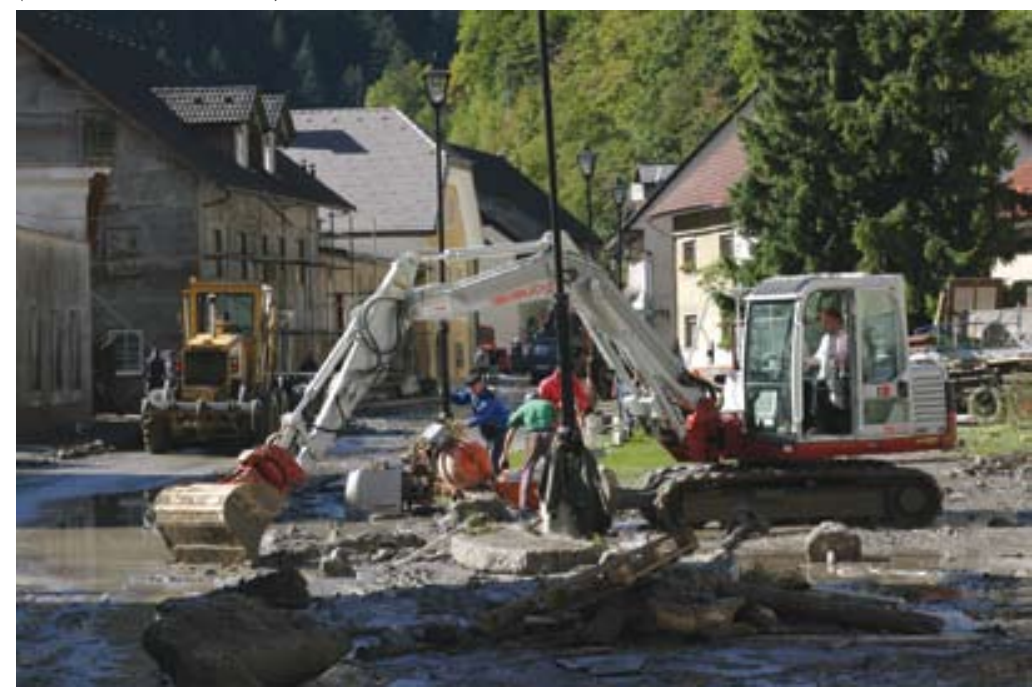

Ker lahko domnevamo, da pri tem napačnem in dolgoročno za družbo škodljivem ravnanju ne gre za namerno 'povzročanje škode', lahko predpostavimo, da je ključni problem v napačnih subjektivnih predstavah o konkretnem prostoru (Natek 2002). Tudi Černe (2005, 240) poudarja velike razlike med objektivno prostorsko stvarnostjo in našim subjektivnim dojemanjem prostora: »Odločitve, ki jih sprejemamo glede načrtovanja prostora, so zasnovane s prostorom kot ga zaznavamo, in ne s prostorom, kakršen je. Ukrepi, ki sledijo odločitvam, pa se na drugi strani odvijajo s stvarnim prostorom in vplivajo na stvarne prostorske razmere.« Če torej ne vidimo nevarnosti naravnih nesreč, jih pri načrtovanju prostorskega razvoja pač ne upoštevamo! Ali se bomo znali izmotati iz te zanke subjektivnega dojemanja/zanikovanja obstoja naravnih nesreč kot objektivne sestavine pokrajinske (prostorske) stvarnosti, pa ne bi smelo biti odvisno samo od še bolj bolečih izkušenj ob prihodnjih naravnih nesrečah, temveč predvsem od boljšega poznavanja in upoštevanja naravnih danosti, kar nedvomno ostaja tudi pomembna naloga geografije. 


\section{SKLEP}

V sedanjem času lahko jemljemo ogroženost zaradi poplav kot najnazornejši primer napačnega ravnanja z območji, ki jih ogrožajo destruktivni naravni procesi/dogodki. Primarna funkcija poplavnih območij je namreč odvajanje občasnih presežkov poplavnih voda, ki se lahko pojavljajo bodisi vsako leto, ali pa v tako dolgih časovnih presledkih, da spomin na to delovanje zamre med domačim prebivalstvom in med strokovnjaki, ki odločajo o uporabi tega prostora za najrazličnejše človekove dejavnosti. Sledovi delovanja teh naravnih procesov v pokrajini niso vedno neposredno vidni, zato imajo geografija in druge stroke zelo pomembno nalogo njihovega identificiranja ter iskanja možnosti za sobivanje med temi naravnimi procesi in človeško družbo v smislu sonaravnega razvoja. Podobno velja tudi za druge naravne nesreče, ki obstajajo kot konkretne sestavine pokrajine oziroma prostora (npr. vremenske ujme kot so suša, pozeba, žled, viharni vetrovi), a jih ne moremo v celoti kriviti za velike škode in druge 'nevšečnosti', saj lahko velik delež tega pripišemo neustreznemu človekovemu ravnanju in nesmotrni rabi prostora, brez upoštevanja naravnih omejitev in zmogljivosti okolja na lokalnem in regionalnem nivoju.

Solidno zasnovane zakonske osnove (npr. Zakon o vodah, Zakon o prostorskem načrtovanju) in drugi dokumenti (npr. Strategija prostorskega razvoja Slovenije, Direktiva Evropskega parlamenta in sveta o oceni in obvladovanju poplavne ogroženosti) se z vidika groženj prihodnjih naravnih nesreč premalo dosledno izvajajo. S tem napačnim ravnanjem se pogosto povsem po nepotrebnem izpostavljamo še hujšim posledicam prihodnjih naravnih nesreč in oddaljujemo od deklarativnih ciljev uveljavljanja sonaravnega/trajnostnega razvoja družbe. Ker ima pri odločanju o tem veliko težo subjektivno dojemanje ogroženosti zaradi naravnih nesreč tako pri lokalnem prebivalstvu kot pri načrtovalcih, to pa je praviloma neskladno z objektivno stvarnostjo, imajo geografija in druge stroke izjemno pomembno nalogo pri preučevanju pokrajinskih sestavin, ki vsebujejo informacije o preteklih in prihodnjih naravnih nesrečah, ter pri prizadevanjih za čim tehtnejšim vključevanjem tega znanja v prostorsko načrtovanje in druge človekove dejavnosti v prostoru s ciljem udejanjanja paradigme sonaravnega razvoja.

\section{Viri in literatura}

Černe, A. 2005. Pandorina skrinjica - geografski pogledi na prostorske analize v planiranju. Dela, 23, 235-244. Ljubljana

Direktiva 2007/60/ES Evropskega parlamenta in sveta z dne 23. oktobra 2007 o oceni in obvladovanju poplavne ogroženosti. Medmrežje: http://eur-lex.europa.eu/LexUriServ/ site/sl/oj/2007/1_288/1_28820071106s100270034.pdf(15.12.2007).

Dobravc, M. 2003. Poplavna ogroženost doline ob spodnjem toku Gradaščice in severnega dela Ljubljanskega barja. Diplomsko delo, Oddelek za geografijo Filozofske fakultete. Ljubljana.

Gams, I. 1955. Snežni plazovi v Sloveniji v zimah 1950-1954. Geografski zbornik, 3, 121-219. Ljubljana. 
Gams, I. 1983. O razsežnosti in potrebnosti raziskovanja naravnih nesreč v Jugoslaviji. V: Naravne nesreče v Jugoslaviji s posebnim ozirom na metodologijo geografskega preučevanja, 5-16. Ljubljana.

Gašperič, P. 2004. The expansion of Ljubljana onto the Ljubljansko barje moor. Acta geographica Slovenica, 44-2, 7-33. Ljubljana.

Melik, A. in sod. 1954. Povodenj okrog Celja. Geografski vestnik, 26, 3-58. Ljubljana.

Najboljše prakse za preprečevanje poplav, varstvo pred njimi in ublažitev njihovih posledic. Medmrežje:http://www.dhd.si/datoteke/strategija_poplave_koncni_prevod.pdf (11.12.2007).

Natek, K. 2002. Ogroženost zaradi naravnih procesov kot strukturni element slovenskih pokrajin. Dela, 18, 61-74. Ljubljana.

Natek, K. 2003. Fizična geografija in preučevanje ogroženosti zaradi naravnih in drugih nesreč. Dela, 20, 133-144. Ljubljana.

Natek, K. 2005. Poplavna območja v Sloveniji. Geografski obzornik, 52, 1, 13-18. Ljubljana.

Orožen Adamič, M. 1995. Earthquake threat in Ljubljana (Potresna ogroženost Ljubljane). Geografski zbornik, 35, 45-112. Ljubljana.

Plut, D. 2004. Geografske metode preučevanja degradacije okolja. Ljubljana.

Plut, D. 2005. Teoretična in vsebinska zasnova trajnostno sonaravnega napredka. Dela, 23, 59-113. Ljubljana.

Poplavna ogroženost ljubljanskega območja. Medmrežje: http://www.mop.gov.si/fileadmin/ mop.gov.si/pageuploads/dokumenti/poplavna_varnost_Ljubljane.pdf (21.12.2007).

Privšek, A. 2007. Geografski učinki poplave 1.11 .1990 v Zgornji Savinjski dolini in njihovo upoštevanje pri načrtovanju prostorskega razvoja. Diplomsko delo, Oddelek za geografijo Filozofske fakultete. Ljubljana.

Radinja, D. 1983a. Naravne nesreče v geografski luči. V: Naravne nesreče v Jugoslaviji s posebnim ozirom na metodologijo geografskega preučevanja, 17-29, Ljubljana.

Radinja, D. 1983b. Žledne ujme v Sloveniji. V: Naravne nesreče v Sloveniji, 107-115. Ljubljana. Strategija prostorskega razvoja Slovenije. Ljubljana 2004.

Šifrer, M. 1977. Geografski učinki žleda v gozdovih okrog Idrije in Postojne. Geografski zbornik, 16 (1976), 195-228. Ljubljana.

Zakon o prostorskem načrtovanju. Uradni list Republike Slovenije, 33/2007. Ljubljana.

Zakon o vodah. Uradni list Republike Slovenije, 67/2002. Ljubljana.

\section{GEOGRAPHICAL DIMENSIONS OF NATURAL HAZARDS AND THEIR PREVENTION}

\section{Summary}

Natural hazards are, from geographical point of view, component parts of geographical space and they had to be considered as such in everyday life and, also, in spatial planning. It is possible to identify their presence in space with geographical methods of investigation, to determine their effects on nature and society and, on this base, to search for possibilities 
of coexistence with them by spatial planning instruments. We can distinguish at least four spatial elements, connected with presence of natural hazards (Natek 2002): direct effects of natural events/processes (e.g. landslides, rockfalls, torrential alluvial fans), elements showing the awareness of local people in avoiding endangered areas (e.g. avalanche paths, flood areas, active alluvial fans), protective constructions (e.g. artificially raised construction sites, earthquake-prone buildings, diversion channels) and negative experiences with natural hazards (e.g. inappropriate bridges on torrents which stop the flow of flood-water, erosion of artificially strengthened river banks, soil erosion).

Natural hazards are not always directly visible, because they are mostly short-lived phenomena and, therefore, it is hard to identify them during periods between particular events. This is directly linked with subjective perception of natural hazards in space and time among local population and also among spatial planners, which is usually very different from actual (objective) situation. Right here, the geographical methods are very successful, because they enable us to identify and explain cause-and-effect relations in the region, the links between natural and social factors, differences in spatial distribution of phenomena and changing of phenomena and their mutual relations through time.

Radinja (1983a) has introduced the term 'prognostic geography' in connection with studying of regional differences, intensity and frequency distribution of natural hazards in space and time, what can be considered as elements for risk analysis of particular area and, therefore, not very distant from prognosis. Actually, the stress is on evaluation of certain phenomenon or/and of its function in the area, which is derived from previous development of the phenomenon alone and, at the same time, considers the existing social conditions and their quick changing. The relationship between nature and society also changes with general evolution of the particular society. Not long ago 'masters of nature', we slowly start to realize that we can survive only with the enforcement of sustainable development, based on consideration of natural circumstances and restraints but, natural hazards and their effects on the society are also changing simultaneously with the evolution of society, one more evidence for very geographical essence of these events/processes.

The introduction of spatial dimension in context of paradigm of sustainable development is of great importance for geography, because it contributes the complexity of regions (environment, space), especially from point of view of mutual influences between nature and society, and the diversity of 'spatial arena' (Plut 2004, 22), where very different social-geographic, sociological, economic and other systems exist besides natural ones. Already, Plut $(2005,101)$ found out that, until now, the spatial and/or regional dimension of sustainable development was considerably neglected, so the role of geography could be in »... emphasizing the importance of adaptation of settlement patterns, economy, infrastructure and land use to regional/spatial characteristics and processes for achieving the optimum of sustainability."

Natural and social processes do not work in an abstract, uniform space but, they are, at the same time, the cause and consequence of diversity of region (space) in which the individual elements have very different dynamics and functions. The acceptation of this geographical dimension by the society can be an important contribution to more stable, sustainable development, because $\gg .$. regionally (or locally) comprehended sustainability... 
means the adaptation of human activities to regional/spatial restraints and continuous use of regional resources in such a way that the development will not endanger the functioning of the region and neighboring areas, without burdening the planetary ecosystem." (Plut 2005, $65)$.

From the point of view of natural hazards the largest attention should be paid to those areas where the intensity of natural processes is particularly strong. According to the paradigm of sustainable development, in such areas the natural processes must have the priority before current needs of society. The location of unsuitable activities in such areas is, unfortunately, a widespread practice not only in Slovenia, however, the sustainable development cannot be carried out without assuring the full functionality of these areas for prevailing (often harmful) natural processes.

In accordance with the Slovene legislation and European Directive 2007/60/EC on the assessment and management of flood risks, the maintenance and/or restoration of floodplains should be the primary task instead of large constructional interventions (e.g. construction of large detention basins). According to the Directive 2007/60/EC »the member states shall establish appropriate objectives for the management of flood risks, ... focusing on the reduction of potential adverse consequences of flooding for human health, the environment, cultural heritage and economic activity, and, if considered appropriate, on non-structural initiatives and/or on the reduction of the likelihood of flooding «.

Large structural interventions would have to be the last solution because of large environmental and financial costs, when there is really no other possibility for reduction of flood risk. To the contrary of existent practice, when such decisions are accepted from case to case, they should be derived from an integral strategy of flood risk reduction. Considering the effectiveness of previous flood-prevention works in Slovenia (e.g. the failure of floodprevention measures in northern parts of Celje as demonstrated by floods of 18 September 2007), the construction of large detention basins without any integral strategy will only bring the (false) feeling of 'perfect' safety from floods and, therefore, even more spreading of settlements, infrastructures and other activities on floodplains. The effects of such good intentions would be the opposite of the expected outcome - the increase of long-term flood risks, especially in context of global climate changes.

Also in Slovene legislation (Waters Act, Spatial Planning Act), the sustainable approach in managing of flood areas and other areas of intensive natural processes is well established on the declaratory level but, the practical enforcement of this legislation is rather weak. This is one reason, why every larger flood inundates and damages not only the older residential, industrial and other buildings but also many newly-built buildings that should never be situated in the 'areas of harmful natural processes'. From point of view of sustainable development and environmental ethics, this is an unacceptable practice, because $\gg .$. spatial planning may not look on satisfying the needs of existent society for space only, but, according to the idea of environmental ethics, it should also consider the intergenerational responsibility.« (Plut 2005, 62). Disregarding the presence of natural hazards in region (space) is strongly reducing the environmental capacity and its self-regulatory abilities and the consequence is the increase in damage due to natural disasters and, also, of social instability and inequity. The simple profit-making approach to areas of intensive and harmful 
natural processes decreases the stability of natural processes and triggers adverse effects on other places and not guilty people and, also, avoidable expenditures from state and municipal budgets.

It is obvious that all the flood management in the past was done with good intentions, so we can suppose the problem is lying in misleading (wrong) subjective perception of natural hazards in space and time (Natek 2002). If we do not see the risk of natural hazards and, if we are not aware of its presence in the region, we just cannot consider them in spatial planning! Finding the way out of this sling of subjective perception/denying of natural hazards should not depend only on even more painful experiences, damages and victims of future natural disasters but, above all, on better knowledge and consideration of natural circumstances what, without any doubt, remains an important task of geography. 